\title{
PHOTO NOTES
}

\section{SANDHILL CRANES}

On 24 June 2009, I noticed two Sandhill Cranes grazing in our wheat field so I went out and got very close to what I assume was their nesting site. I took a couple of quick pictures then left them alone. As July progressed, we occasionally saw the cranes out feeding, but always from a distance.

On 29 July around 08:00 h, my sonin-law was driving west of our farm in his (very noisy) one-ton Dodge diesel truck. He noticed a crane chick and two adults in the road ditch. As he attempted to drive past them, one adult crane flew up onto the road and stood in front of his truck. Knowing his mother-in-law (i.e, me) fairly well, he immediately phoned me to bring my camera. I arrived within 2 minutes and couldn't believe my eyes. The crane was acting like a Killdeer, attempting to draw us away from the chick. Meanwhile, the other adult disappeared into the wheat field with the chick. That adult later reappeared and flew toward a nearby slough. The crane on the road did some more moves: one minute it pretended to be injured and the next minute it made itself as threatening as possible. When it felt that the other adult was in the clear, it then flew toward the slough and rejoined its mate. After this incident we regularly saw all three of them out in our pea field grazing. One day as we drove by, the chick hid behind a large weed in the field, plainly visible, but I guess it felt safer.

I am pleased to report that at the end of April 2010, we noticed two adult Sandhill Cranes grazing in the same location as I had seen them in 2009 , so hopefully they will have a successful year again.

- Sharon Walker; E-mail: <sharon. walker@sasktel.net>
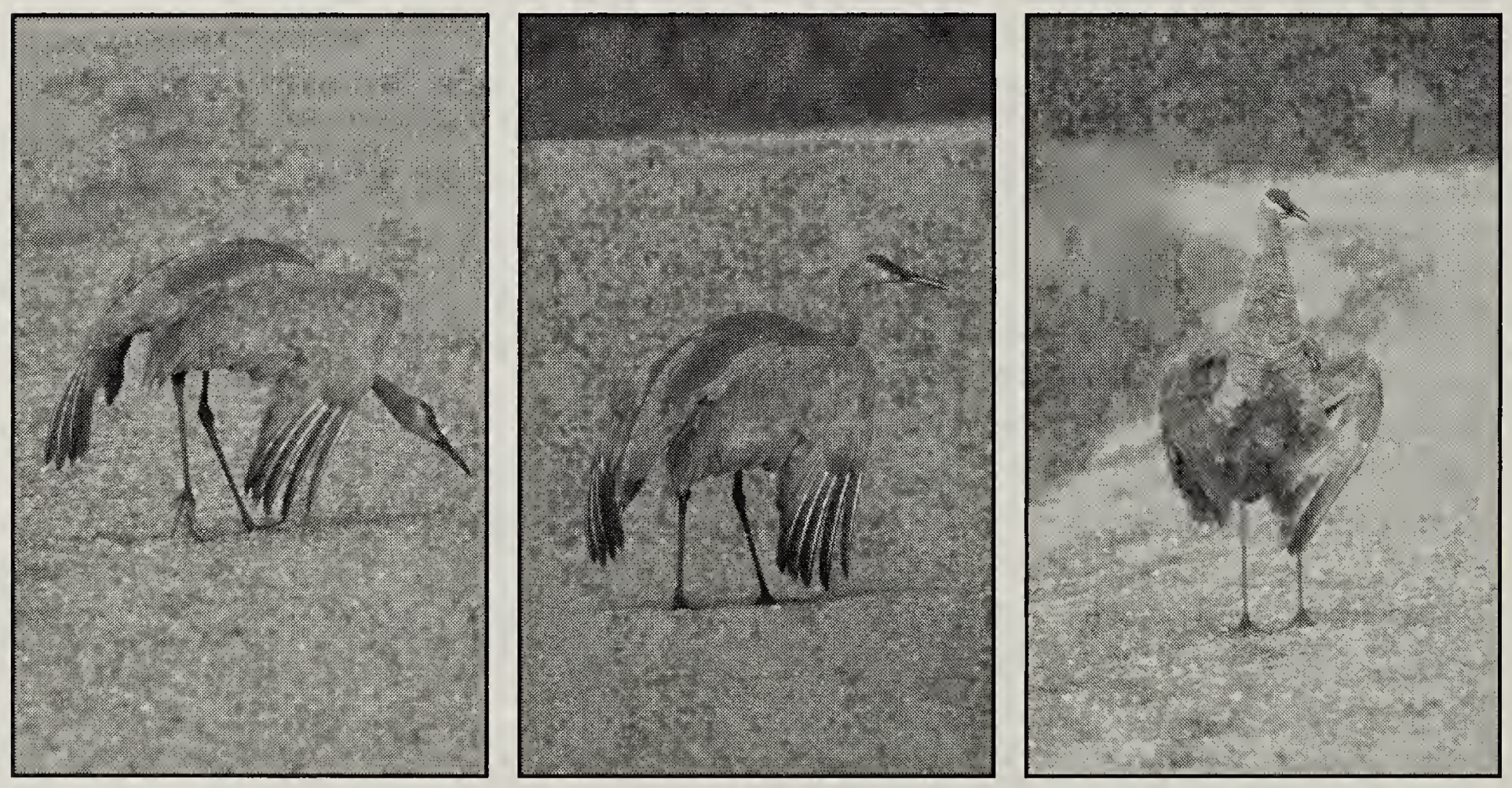